\title{
ARCABUZ DE RUEDA ALEMÁN DEL SIGLO XVII EN EL MUSEO ARQUEOLÓGICO DE MADRID
}

\author{
POR \\ MARIA ROSARIO MARCO RODRIGUEZ
}

Mi agradecimiento al señor Claude Blair, Londres, por los datos que tan amablemente me ha facilitado.

\section{INTRODUCCIÓN}

Durante el siglo xvi Alemania y Austria predominan en la fabricación de armas de calidad, sobre todo hasta la Guerra de los Treinta Años, en que los armeros se ven precisados a emigrar a otros lugares de Europa aportando su técnica y haciendo florecer otros núcleos.

Durante el período que abarca los siglos XVI y XVII, arcabuces y pistolas se consideran como obras de arte. No se llevan las armas únicamente por su utilidad, sino para lucimiento de su decoración. Al igual que las armas blancas, las portátiles de fuego sufrieron la influencia de las artes y sus cajas se ornamentaron con una decoración más o menos rica y apropiada. Dicha ornamentación es muy similar a la que se utiliza para decorar relojes, cajitas, cintillos, botones, empuñaduras de látigo, etc.

En Europa, toda la decoración se inspiraba en diseños publicados por los grabadores de renombre, a excepción de pequeños núcleos provincianos que conservaban su estilo local. En Nuremberg y Augsburgo, los motivos de grabado para las piezas metálicas del arma eran sacados principalmente de las obras de Jost Amman o Virgil Solis y otros que más adelante se citarán.

En un principio aparecieron series de motivos grabados destinados a todos los cinceladores en general, pero, por su perfección y otras dificultades obvias, resultaban muy difíciles de ejecutar en las superficies tan irregulares que presentan las armas de fuego.

El problema quedó resuelto al publicarse series de diseños concebidos especialmente para tal uso, y a medida que se avanza hacia el siglo xvII, y parte de él, la caja va cambiando hasta hacerse más y más rica.

Ya se comprende que este género de armas era puro lujo y merecen ser conocidas por el arte en ellas desarrollado.

Las cajas decoradas perduran en Europa hasta el primer tercio del siglo xvir y mucho más en otros centros alejados de la influencia europea. 
Esa moda interesó vivamente a los orfebres, pero desgraciadamente son contadas las piezas de dicha orfebrería que han llegado hasta nosotros.

De ellas podemos citar la joya «Pasfield», de la que en apartado posterior se hablará.

Otros dos ejemplares curiosos, por su mezcla de arcabucería y relojería, son los presentados en los Estados Unidos, por la Fundación Pestalozzi, en la exposición de autómatas.

Muy interesante es la carabina de rueda que perteneció a Rodolfo II y que se encuentra actualmente en el Kunsthistorisches Museum de Viena.

$Y$, por último, queda hablar del arcabuz de caza, recubierto de placas metálicas doradas con decoración de esmaltes y pedrería que se halla en el Museo Arqueológico Nacional de Madrid (Fig. 1).

$$
* * *
$$

Este arcabuz pertenece al lote que integró los primeros fondos del Museo Arqueológico Nacional, proveniente del Gabinete de Historia Natural.

Su caja es de madera recubierta en su totalidad de unas planchas de latón dorado. Dichas planchas se recubren a su vez con una profusa decoración vegetal y floral compartimentada por hileras de «granates de Alemania» ${ }^{1}$. Los esmaltes se ajustan a las placas mediante tornillos de cabeza floriforme y otros más menudos (Figs. 2-3).

La baqueta se remata en latón trabajado todo él y se sujeta mediante dos anillas de granates (Fig. 5).

El guardamonte tiene tres muescas destinadas a los dedos y está cincelado con motivos florales y adornado con granates también. Este tipo de guardamonte muescado es muy típico de las armas de caza alemanas.

La caja corresponde también a la tipología de las armas de rueda alemanas, realizadas desde finales del siglo XvI en adelante. Se apoyan en la mejilla sin peligro, pues el peso del cañón absorbe el retroceso. Howard L. Blackmore, en su trabajo sobre armas ${ }^{2}$, la clasifica como modelo 904.

La llave es de rueda y está introducida en el interior de la pletina según la técnica que se sigue a partir de mediados del siglo Xvir ${ }^{3}$, quedando, por tanto, las superficies de dicha pletina libres para la decoración, que

1 Denominación que reciben estas piedras en el siglo xv11.

2 HownRD L. Blackmore: «Guns and Rifles of the World», p. 106.

${ }^{3}$ Generalmente sucede así, pero se encuentran excepciones y variantes, tanto de anticipación como de retroceso. 
es la misma que la de la caja, con la introducción de siete amatistas que rodean la llave, más tres en el costado izquierdo, que, sumadas a los granates, hacen un total de 1.157 piedras $^{4}$ (Fig. 3).

El gatillo es simple en extremo y ya no nos recuerda para nada aquel otro de gran tamaño y semejando un dragón. La pirita se conserva en buen estado.

Tiene doble disparador o percutor, que es un invento casi contemporáneo a la llave de rueda y que resulta mecánicamente perfecto desde sus comienzos, por lo que perdurará, sin cambio alguno, en las armas de com-

F1G. 1.-Arcabuz de rueda alemán en el Museo Arqueológico de Madrid.

petición tan tardías como las carabinas del llamado «modelo Creedmore» de los años 1870-1880.

El mecanismo de las armas de rueda es muy ingenioso. Con su inven. ción se suprime la mecha, y la inflamación de la pólvora se efectúa por medio de las chispas que produce el roce de una pequeña rueda de acero con la pirita de azufre como piedra.

La piedra está sujeta entre dos placas de hierro y al ponerse la rueda en movimiento, por medio de un resorte interior, al rozar rápidamente con el acero se producen las chispas que van a inflamar la pólvora de la cazoleta.

Entre los inconvenientes de este mecanismo hemos de citar la facilidad con que podía inutilizarse y la necesidad de un especialista para su arreglo; lo engorroso de la carga, pues había que dar cuerda a la rueda al igual que un reloj, y por último, debe tenerse en cuenta que las armas portadoras de este mecanismo resultaban caras y por ello en un principio sólo se usaron en círculos muy restringidos.

No obstante, y pese al edicto de 1517 dado por Maximiliano I, prohibiendo su fabricación y dándose las mismas prohibiciones en Ferrara,

${ }^{4}$ En la actualidad se han perdido algunas. 
Módena, Milán y Florencia en 1522, la invención de la llave de rueda contribuyó a la invención de armas portátiles de menor tamaño, como el pistolete y el pedreñal, petrinal o poitrinal ${ }^{5}$.

En un principio, la rueda estaba al exterior y su timbre se cubría con placas profusamente decoradas. En su evolución la rueda pierde su timbre y todo el mecanismo queda en el interior de la pletina, dejándola libre para su decoración.

Entre los dibujos de Leonardo da Vinci se halla el de un proyecto de llave de rueda, que sin duda fue el primero, ya que puede fecharse entre 1482 y 1499.

Hacia principios del siglo xvi (1509 aproximadamente), los armeros de Nuremberg comenzaron a fabricar las primeras armas de rueda, y las piezas más antiguas que actualmente conocemos son de esta fecha, pudiéndose considerar como auténticas obras de relojería.

Tanto Italia como Alemania se disputan la paternidad de tal invento. Los primeros se apoyan en el Codex Atlanticus de Leonardo da Vinci, que posee dibujos de detalles de una llave de rueda ${ }^{6}$.

Los segundos atribuyen el invento a Johann Kiefuss, de Nuremberg, pero su figura no está documentada y resulta algo mítica.

La primera noticia exacta, hasta ahora conocida, es la de Wilhelm Rem, en la Crónica de Augsburgo, describiendo un desgraciado accidente al manipular un arma de este tipo. Dicha crónica está fechada en 1515.

Hay noticias algo posteriores con respecto a la prohibición de su uso, ya citadas anteriormente.

El cañón es largo y octogonal y se halla algo oxidado, aunque conserva gran parte del empavonado. Carece de inscripción ni marca alguna. Su cola de asiento es lisa y su tornillo posterior tiene como cabeza un grueso granate (Fig. 5).

El ánima del cañón está fuertemente rayada.

En los Archivos del Museo Arqueológico Nacional hay legajos del siglo XIX, muchos de ellos sin fecha, en que aparece citada el arma objeto de nuestro estudio:

Legajo 7-4 (en papel de 1867). Manuscrito del catálogo del Museo Arqueológico; el n. ${ }^{\circ} 295$ corresponde al arcabuz describiéndolo: «Escopeta italiana del siglo xvir. Arma lujosísima adornada con numerosos granates y ricos esmaltes. Longitud, 1,13 metros. La adornan 1.197 piedras. Procedente de Historia Natural.»

s Del francés poitrine $=$ pecho.

- Leonardo da Vinci: Codex Atlanticus, folio 56 b. 
Legajo 11-7 (sin fecha). El arcabuz aparece catalogado con el número 2.269 y descrito: «Escopeta árabe. Adornada con numerosos granates. Longitud, 1,13 metros. Tiene caja con igual número.»

Legajo 12-3 (sin fecha). Aquí figura con el n. ${ }^{\circ}$ 1.494: «¿Escopeta árabe? Adornada con numerosos granates. Longitud, 1,13 metros. Tiene su caja con igual número. Procede del Gabinete de Historia Natural.»

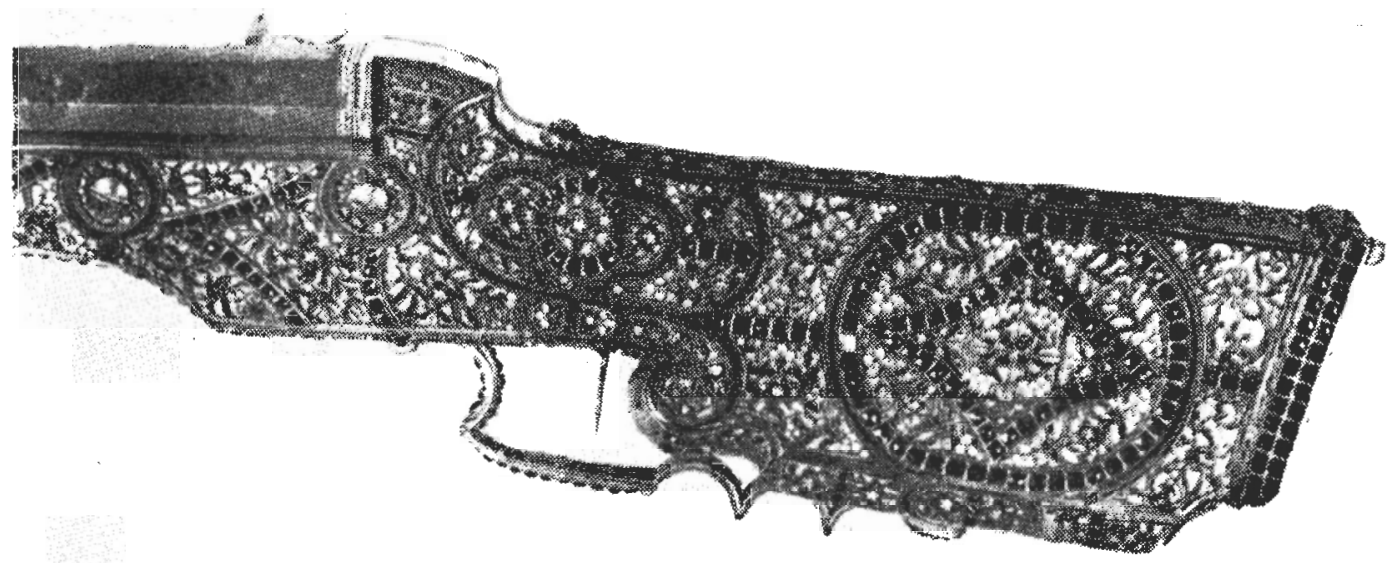

FIG. 2.--Detalle del arcabuz con ornamentación en piedras finas. La caja cubierta de planchas de latón dorado, ornamentos de ugranates de Alemania» y esmaltes cijustados mediante tornillos con cabezas floriformes.

Se le pone el nuevo número 2.559 , que es el que perdura en la actualidad. Se ve que el que hizo este inventario copió del anterior, pero no quedó muy conforme con el origen de fabricación, aunque no supo ver otro.

En el fichero realizado a principios de nuestro siglo la pieza queda reseñada como: «Arcabuz de rueda. Madera, hierro, pedrería y esmaltes. Estilo florentino. Longitud, 1,14 metros. Siglo xviı. Año 1614. Procedencia desconocida. Adquirido por traslación del Gabinete de Historia Natural. Lleva la caja cubierta de 1.157 piedras, en su mayoría granates, y alternando con ellas adornos esmaltados. El número de inventario con que figuraba en el Gabinete de Historia Natural era el 1.494. Figura una 
nota a lápiz, sin duda alguna posterior, que dice: 'Según el S. Meana: alemán (Tirol o Nuremberg por el cañón rayado)'.»

En el catálogo de 1917, que contiene la historia de la fundación del Museo, se hace una concisa y nada reveladora referencia del arma: "Pieza de verdadero lujo es el arcabuz de rueda adornado con profusión de granates y esmaltes construido en el siglo Xviı» ${ }^{7}$.

En la segunda edición de Una visita al Museo Arqueológico Nacional ${ }^{8}$ leemos: "La segunda mesa-urna al lado del muro N..., conserva el valioso arcabuz (n. ${ }^{\circ}$ 2.559), con ornamentación de esmaltes y piedras finas, entre ellas 1.155 rubíes y es discutida su procedencia y arte, pues para algunos es obra italiana del siglo xvil, si bien en una nota que figura en el Museo consta, según declaración del poseedor, cuando por orden de Carlos III se entregó el arcabuz al Museo de Ciencias Naturales en 1782, que la tenían por obra chinesca y que venía en poder de la familia desde el siglo anterior y fue comprado por don Juan Pérez Martínez, en Cantón. Se guardó por los descendientes en Soria.»

Consultados los documentos del Museo, éste al que se hace referencia no figura y sí un libro de entrada de las piezas en el que aparece como: «... procedente del Gabinete de Historia Natural», con descripción del arma, fecha y nada más.

En los sucesivos catálogos no figura nada de interés con respecto a la pieza que nos ocupa.

En el fichero hecho en 1970 esta arma queda catalogada como: «Florentina comprada en Cantón», sin duda alguna basándose en los datos expuestos en Una visita al Museo Arqueológico Nacional.

Don J. M. Echeverría incluye fotografía del arma en la portada de su libro ${ }^{9}$ y en el interior, cuyo pie de foto es: «Rifle de rueda, siglo XviI», pero no hace más comentario.

En un reciente articulito anónimo publicado en la revista «TG» ${ }^{10}$ se aportan datos expresados por el autor anteriormente citado y probablemente basados en los adicionales del fichero de principios de siglo, del Museo Arqueológico Nacional.

En este artículo se da, con casi seguridad y sin fundamento alguno, como propietario al príncipe Baltasar Carlos.

7 Catálogo del Museo Arqueológico Nacional, Madrid, 1917, p. 151.

- Alvarez Osorio, F.: Una visita al Museo Arqueológico Nacional, 2." edición.

9 Echeverría, J. M.: Coleccionismo de armas antiguas, Everest, 1973.

10 Revista «TG», n." 10, Madrid, 1975, p. 46: «EI arcabuz de gala y caza del Príncipe Baltasar Carlos». 
La única monografía seria sobre el arma, hasta el momento, es la de Manuel de Assas ".

En este artículo se narra el compromiso matrimonial entre los padres de don Rodrigo Díaz de Vivar ${ }^{12}$ y el nacimiento y bautizo de éste en Madrid, por cuyo motivo se regala al Príncipe de Asturias, más tarde Feli-

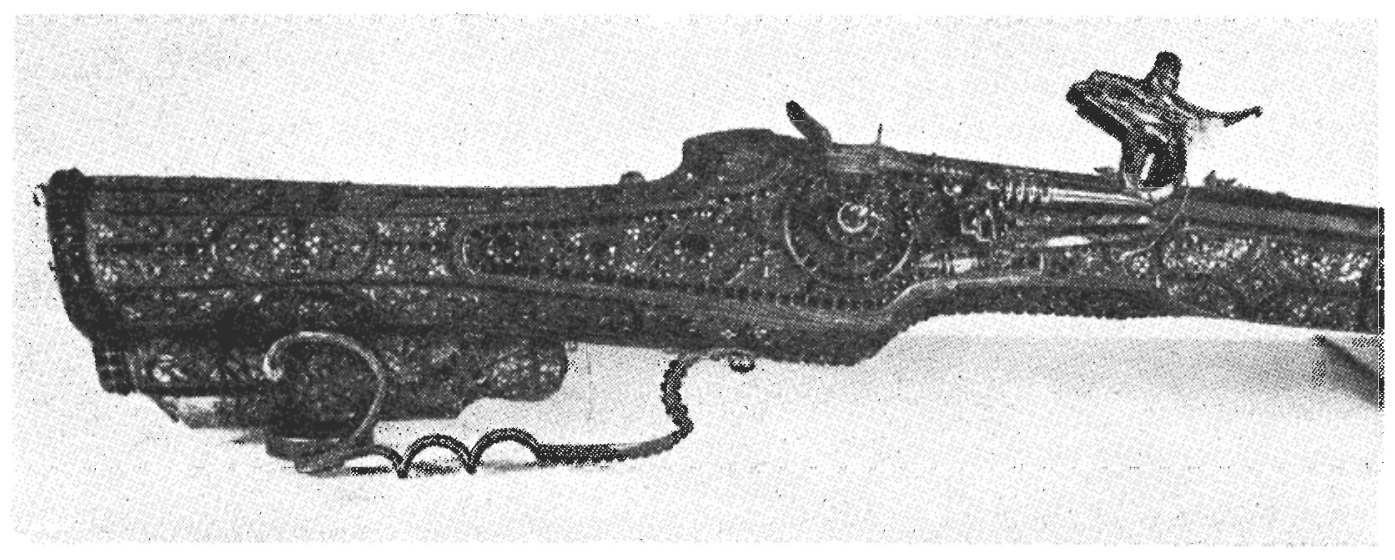

Fig. 3.-El otro lado de la culata de la caja, con llave de rueda y guardamonte.

pe IV, «un arcabuz curiosísimo guarnecido de oro». Todo ello sacado de la narración manuscrita del jesuita P. Hernando Pecha.

El señor Assas identifica el arcabuz, regalado por los duques del Infantado al Príncipe, como el existente en el Museo y extraído, en abril de 1813, por los franceses, siendo devuelto por vía diplomática, en junio de 1816, designándola como: «Una preciosa escopeta guarnecida de granates con el gatillo al revés.» Podemos afirmar que nuestra pieza se trata de un arcabuz de indudable fabricación alemana por sus características tanto técnicas como decorativas.

El cañón es octogonal y con el ánima profundamente rayada, características ambas de los cañones alemanes.

En cuanto a la opinión expresada por don Manuel Assas, basada en la de Eusebio Zuloaga, creyendo que no es el original, pues debería estar

$"$ Assas, M. de: Arcabuz o escopeta de rueda del siglo XVII, en «Musco español de antigüedades», t. V, Madrid, 1872, pp. 123 y ss.

${ }_{12}$ Rodrigo Díaz de Vivar, duque del Infantado y virrey de Sicilia en 1653, nacido en Madrid el 3-IV-1614 y bautizado veinte días después en San Andrés. 
ornamentado con diamantes, no tiene fundamento alguno, ya que en otras armas, de la misma época y estilo, el cañón aparece liso, sin ornamentación alguna.

En lo que respecta a la caja, forrada toda ella de metal, tampoco es caso único. Se sabe que su uso no era infrecuente desde el siglo Xvi, y en el Inventario Iluminado de Carlos $\mathrm{V}$ podemos ver un ejemplar de pistola aunque sin pedrería.

En nuestros días se conservan pocas piezas, lo que nos hace considerar su rareza. Estas piezas son las ya citadas anteriormente:

La joya «Pasfield», de marcada influencia alemana, que data del si-

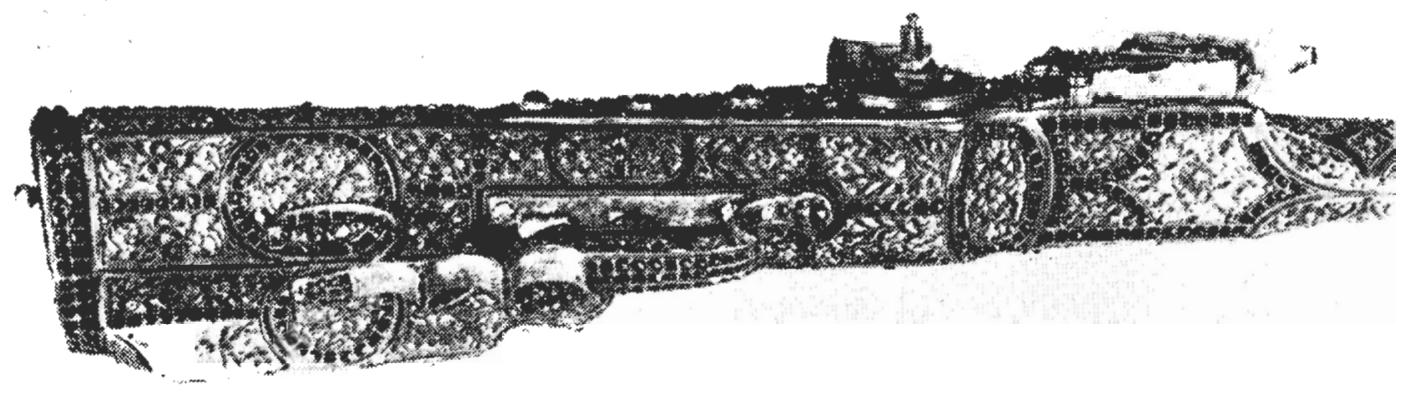

FIG. 4.--Detalles del guardamonte y la ornamentación vistos del lado interior.

glo Xvi, estudiada por J. F. Hayward ${ }^{13}$. Es de oro, recubierta por un arabesco de pequeños dibujos en esmalte, con probables colores azul y rojo (quedó en malas condiciones tras el incendio de 1817), teniendo engarzadas tres esmeraldas en la parte superior (una actualmente desaparecida). También ofrecen interés dos ejemplares presentados en la exposición de autómatas en Estados Unidos ${ }^{14}$, con rica decoración de perlas y pedrería.

Otra pieza, que al igual que las anteriores ya se citó en la introducción, es la carabina de rueda que perteneció a Rodolfo II. Tiene una fina decoración de esmaltes sobre placas de plata hecha por David Altensletter, orfebre de Augsburgo (ca. 1610) y cuyas llave y cañón están cinceladós por Daniel Sadeler.

${ }^{13}$ Havward, J. F.: English pistols of the 17 th century, en «Apollo», XLVI, año 1947, pp. 94 y ss.

${ }^{14}$ Catálogo exposición de autómatas, 1950. 
Son también del mismo orfebre una pareja de pistolas de arzón, hechas para Cristián IV de Dinamarca, con guarniciones de oro con esmaltes y piedras preciosas, que han llegado a nuestros días modificadas, pues sus llaves de rueda se cambiaron por las de sílex que actualmente ostentan.

La decoración esmaltada de nuestro arcabuz no ofrece particularidad alguna si repasamos los diseños que aparecen grabados en Alemania en el siglo XVI.

Paulus Birckenhultzf crea motivos muy semejantes a éstos, ante todo uno con una cartela central cuya leyenda es: «Varii generis opera aurifabris necesaria», aunque sus líneas son más ondulantes, pues éstas objeto de nuestro estudio pecan de una cierta rigidez.

Hay otros muchos grabadores con diseños semejantes, entre los que

Fig. 5.-El cañón con su caja decorada y baqueta en latón.

podríamos citar a Friedrich Brentel, Anton Eisenhoit, Flötner e incluso el mismo Holbein ${ }^{15}$.

Parece extraño que citemos grabados del siglo XvI al tratar una pieza del Xvir, pero sabido es que salvo Munich los demás centros armeros alemanes se aferraban fielmente a los modelos ya establecidos con anterioridad.

La decoración de pedrería tampoco es extraña a su época. Es muy frecuente encontrar en los inventarios del siglo Xvir tabaqueras, relojes, cajas, botones y armas, tanto blancas como de fuego, y precisamente es muy corriente el uso de los llamados «granates de Alemania».

Como apoyo a esta última afirmación puede citarse la orden real, dada el 8 de agosto de 1652, en la que se dice al armero mayor, don Diego de Torres Camargo, «... que se pongan en su armería todas las armas que hubiese en el guardajoyas, pero que no tienen piedras finas ni joyas» ${ }^{16}$.

${ }^{15}$ Ganz, Paul: Two unpublished portraits by Hans Holbein, en «Burlington Magazine», vol. XX, p. 31.

${ }^{16}$ Archivo del Palacio Real de Madrid, C. ${ }^{a}$ 308/15. 
El empleo de metales preciosos y pedrería como adorno de armas se suprimió, salvo alguna rara excepción, a finales de la Guerra de los Treinta Años, en que comienza un período realmente crucial para los armeros, que habían tenido una gran afluencia de pedidos.

Un punto oscuro y que queda por ahora sin aclarar es el saber a quién perteneció el arcabuz.

Manuel de Assas dice que perteneció a Felipe IV, como ya se ha recogido antes en el extracto de su artículo, pero «un arcabuz curiosísimo guarnecido de oro» no es una prueba evidente de que se trate del mismo, y hay que tener en cuenta que nuestro arcabuz no es de oro.

Por otro lado, en una tasación de armas hecha por plateros, agosto de 1616, figuran «cinco arcabuces de cinco palmos con cañón ochavado y placas doradas y decoradas» ${ }^{17}$.

Entre los documentos consultados en el Archivo de Palacio hay uno, del año 1617, correspondiente a los cargos que resultan contra Hernando de Espejo y otras personas de la almoneda de los bienes libres de los reyes don Felipe II y doña Ana, en cuya hoja primera, con el número 825, se inventaría: «Un arcabuz de latón metido en una caja de cuero colorado, dorado, tasado en treinta ducados» ${ }^{18}$.

En efecto, nuestro arcabuz tiene un estuche que corresponde a estas señas. Pero si el arcabuz reseñado en este documento fue efectivamente de Felipe II, no puede ser el nuestro, ya que este rey murió en 1598 y el arcabuz tema de nuestro estudio es del siglo XviI.

En definitiva: hasta el momento no ha sido hallado documento alguno en el que figure, de forma que podamos decir indiscutible, esta arma y, por tanto, no podemos saber quién fue su dueño realmente.

Medidas del arma: Largo total: 1,14 metros. Largo del cañón: 0,87 metros. Calibre: $17 \mathrm{~mm}$. Número de inventario: 52.559 .

\section{B I B L IOGRAFIA}

Barado, F.: Museo militar. Historia del Ejército español, t. III, Barcelona, 1886. Echeverría, J. M.: Coleccionismo de armas antiguas. Edit. Everest, Madrid, 1973. HAYWARD, J. F.: Les armes à feu anciennes, 1500-1660. Office du Livre, Friburgo, 3.² edición, 1970.

Blackmore, Howard L.: Guns and Rifles of the World. London, 1965.

Lindsay, M.: Histoire des armes à feu. Ol/ice du Livre, trad. J. R. Clergeau, Friburgo, 1972.

Alvarez Osorio, F.: Una visita al Museo Arqueológico Nacional, 2." edición.

17 Ibid., C. $308 / 5$.

${ }^{18}$ Ibid., Leg. 765. 
Assas, M. de: Arcabuz o escopeta de rueda del siglo XVII, en «Museo español de antigüedades», Madrid, 1872, t. V.

Catálogo del Museo Arqueológico Nacional, Madrid, 1917.

Catálogo exposición de autómatas, 1950.

GANz, P.: Two unpublished portraits by Hans Holbein, en «Burlington Magazine», vol. XX.

Revista «TG», n. ${ }^{\circ}$ 10, Madrid, 1975, p. 46: «El arcabuz de gala y caza del Príncipe Baltasar Carlos.» 